\title{
Effects of temperature and salinity on Menidia beryllina embryos exposed to terbufos*
}

\author{
Michael J. Hemmer, Douglas P. Middaugh, James C. Moore
}

U.S. Environmental Protection Agency, Gulf Breeze Environmental Research Laboratory, Sabine Island, Gulf Breeze, Florida 32561, USA

\begin{abstract}
Embryos of the inland silverside Menidia beryllina were exposed to the organophosphorus pesticide terbufos at 9 combinations of temperature $\left(20,25\right.$ and $\left.30^{\circ} \mathrm{C}\right)$ and salinity $(5,12.5$ and $20 \%$ o). Nominal exposure concentrations were $12.5,25,50$ and $100 \mu \mathrm{g}$ terbufos $\mathrm{l}^{-1}$ with an acetone and seawater control for each temperature/salinity combination. Test durations were temperature dependent and ranged from 5 to $14 \mathrm{~d}$. Endpoints were embryo survival, hatching and percentage of larvae with normal vertebrae. Embryo survival was significantly $(\alpha=0.05)$ lower in tests conducted at $20^{\circ} \mathrm{C}$ for all salinities. Salinity affected survival only at combinations of $20 \%$ and $100 \mu \mathrm{g}$ terbufos $1^{-1}$ Both temperature and salinity affected the percentage hatch, with the lowest hatching occurring in tests at $20^{\circ} \mathrm{C}$ and in tests conducted at $20 \%$. The percentage of larvae with normal vertebrae was significantly $(\alpha=0.05)$ reduced from controls at terbufos concentrations of $25(7$ to $32 \%), 50(44$ to $62 \%)$ and $100 \mu \mathrm{g}$ $1^{-1}(58$ to $73 \%)$ for the 3 temperatures tested, whereas salinity showed no significant effect. Anomalies in the development of vertebrae occurred across all temperature and salinity combinations, and were observed at concentrations as low as $12.5 \mu \mathrm{g}$ terbufos $\mathrm{l}^{-1}$
\end{abstract}

\section{INTRODUCTION}

Terbufos (S-[(1,1-Dimethylethy]) thio] methyl] 0,0diethyl phosphorodithioate) is a widely used organophosphorus compound applied as a soil insecticide and nematicide primarily on corn, sugar beets and grain sorghum for protection against a variety of agricultural pests (U.S. Environmental Protection Agency 1983). As of 1983, over 7.9 million acre-treatments (the number of acres treated multiplied by the number of applications) of terbufos were applied in the USA (Smith 1987). Terbufos has been detected in 444 of 2016 surface-water samples from 55 locations, at a maximum concentration of $2.25 \mu \mathrm{g} \mathrm{l}^{-1}$, and in 9 of 283 ground-water samples from 261 sources, at a maximum concentration of $3.0 \mu \mathrm{g}$ $1^{-1}$ (U.S. Environmental Protection Agency 1987).

Studies with aquatic animals are limited to several freshwater invertebrate and fish species. Static $96 \mathrm{~h}$ $\mathrm{LC}_{50}$ 's for technical grade terbufos range from 7.6 to $15.3 \mu \mathrm{g} \mathrm{I}^{-1}$ for rainbow trout Salmo gairdneri, 150 to $390 \mathrm{\mu g} \mathrm{l}^{-1}$ for fathead minnows Pimephales promelas,

- Contribution No. 667, Gulf Breeze Environmental Research Laboratory and 1.1 to $2.4 \mu \mathrm{g} \mathrm{l}^{-1}$ for bluegill Lepomis macrochirus (Mayer \& Ellersieck 1986).

Other organophosphate pesticides with anticholinesterase modes of action have been shown to induce teratogenic responses in developing teleosts. Weis \& Weis (1974) reported that embryos of the mummichog Fundulus heteroclitus exposed to $10 \mathrm{mg}$ parathion $\mathrm{l}^{-1}$ exhibited arrested development and cardiac malformations including tube hearts. In the same study, several mummichog fry developing in $10 \mathrm{mg}$ malathion $\mathrm{I}^{-1}$ exhibited scoliosis. Exposure of Atlantic silversides Menidia menidia to malathion caused optic anomalies such as unilateral and bilateral microphthalmia, unilateral and bilateral anophthalmia and cyclopia (Weis \& Weis 1976). The exposed embryos also showed stunted growth and severe cardiac malformations. Embryos of the Japanese medaka Oryzias latipes expressed anomalies in the shape and number of the heart chambers when exposed to $3 \mathrm{mg}$ parathion $\mathrm{l}^{-1}$ and $10 \mathrm{mg}$ malathion $1^{-1}$, and $100 \%$ of the embryos developed straight tube hearts when tested at 9 and $18 \mathrm{mg}$ parathion $\mathrm{l}^{-1}$ and $40 \mathrm{~m} \mathrm{~g}$ malathion $\mathrm{l}^{-1}$ (Solomon \& Weis 1979).

The purpose of our study was to determine if terbufos was teratogenic to developing Menidia beryllina em- 
bryos, and if so, what influence combinations of temperature and salinity would have on terbufos teratogenicity.

\section{MATERIALS AND METHODS}

Fish. Naturally spawned and fertilized embryos of the inland silverside Menidia beryllina were obtained from a population of adults collected from Robinson Point, Blackwater Bay, Florida, USA, and maintained in the laboratory. The laboratory spawning system was described by Middaugh et al. (1986, 1987). Fertilized embryos in the blastula stage (Lagler et al. 1977) were harvested from spawning substrates on days when tests were started.

Exposures. A $3 \times 3 \times 6$ complete factorial design was used consisting of 3 levels of salinity $(5,12.5$ and $20 \%$ ), 3 levels of temperature $\left(20,25\right.$ and $\left.30^{\circ} \mathrm{C}\right)$ and 4 terbufos concentrations $\left(12.5,25.0,50.0\right.$ and $\left.100 \mu \mathrm{g}^{-1}\right)$ with an acetone and seawater control.

Seawater pumped from Santa Rosa Sound, Florida was prefiltered through $20 \mu \mathrm{m}$ polypropylene filters and secondarily vacuum filtered to $6 \mu \mathrm{m}$. The salinity was adjusted to $5,12.5$ or $20 \%$ using deionized glassdistilled water. The filtrate was then autoclaved in aliquots of $2500 \mathrm{ml}$.

A $1.0 \mathrm{mg} \mathrm{ml}^{-1}$ stock solution was prepared by dissolving terbufos $(86.0 \%$ technical grade, American Cyanamid Co., Princeton, NJ) in nanograde acetone. Exposure concentrations were provided by adding the appropriate amount of stock solution to $1120 \mathrm{ml}$ of the sterile seawater to yield the desired exposure concentrations. The acetone concentration was equilibrated across all exposure concentrations. For each exposure concentration, $120 \mathrm{ml}$ of media was used for exposures, with the remaining $1 \mathrm{l}$ analysed for terbufos concentration at the beginning of each test.

The 11 terbufos samples were extracted twice with $100 \mathrm{ml}$ petroleum ether and concentrated to $1 \mathrm{ml}$. Extracts were analysed by electron capture gas chromatography utilizing a $182 \mathrm{~cm} \times 2 \mathrm{~mm}$ i.d. glass column packed with $2 \%$ SP2100 on $100 / 120$ mesh Supelcoport, at a column temperature of $200^{\circ} \mathrm{C}$. The detector was maintained at $300^{\circ} \mathrm{C}$ and quantification was accomplished with a Hewlett-Packard 3357 Lab Automation System ".

The loading and exposure procedures were similar to those described by Middaugh et al. (1988). Borosilicate glass culture tubes $16 \times 93 \mathrm{~mm}$ (window size $11 \times 55$ $\mathrm{mm}$ ) were used as exposure vessels. A single blastulastage embryo was placed into each of 120 numbered, randomly ordered, culture tubes. The tubes were reor-

\footnotetext{
- Mention of commercial tradenames does not constitute endorsement of the U.S. Environmental Protection Agency
}

dered and $6 \mathrm{ml}$ of clean seawater, acetone-seawater mixture or exposure media was pipetted into 20 respective culture tubes for each concentration or control and sealed with a teflon lined screw cap. Thus, 20 tubes were used for each exposure concentration, and each seawater, and acetone control for all of the 9 salinitytemperature combinations tested. The racked tubes were placed in a horizontal position in an incubator and maintained at the desired temperature $\pm 1{ }^{\circ} \mathrm{C}$ with a $14 \mathrm{~h}$ light: $10 \mathrm{~h}$ dark photoperiod, and a light intensity of $17.5 \mu \mathrm{E} \mathrm{m} \mathrm{m}^{-2} \mathrm{~s}^{-1}$. Daily, each rack was inverted 5 times to facilitate mixing and to reduce the potential for fungal infections (Hemmer unpubl, data).

Observations. Individual embryos were checked $24 \mathrm{~h}$ post-exposiure and then monitored daily until the commencement of hatching. Test duration was temperature dependent, ranging from $14 \mathrm{~d}$ at $20^{\circ} \mathrm{C}$ to $7 \mathrm{~d}$ at $25^{\circ} \mathrm{C}$ and $5 \mathrm{~d}$ at $30^{\circ} \mathrm{C}$. Tubes containing hatched larvae were placed into an ice bath until the cessation of swimming to facilitate observations. A Zeiss Invertoscope D Microscope equipped for photomicrography was used to categorize results, Larvae were scanned for craniofacial and cardiovascular malformations, however, primary emphasis was on observation and quantification of skeletal anomalies. The skeletal deformities were scored using a numerical 'severity-index' (Table 1) which was based on classification schemes devised by Weis \& Weis (1977), Weis et al. (1981) and Weis \& Weis (1982).

At the end of each test, 5 tubes from each treatment were checked for dissolved oxygen content by direct. measurement within each tube using a Lazar DO-166 dissolved oxygen probe. The pH of test solutions in 3 additional tubes were measured from each treatment using an Orion SA 520 pH meter and a Fisher pencil combination electrode. The test solutions were gently stirred during all measurements using $7 \times 2 \mathrm{~mm}$ magnetic stir bars.

Statistical analysis. For each test, the combined percentage survival of embryos and larvae, the percentage hatch of normally developed larvae, and the percentage of larvae with vertebral anomalies was calculated for each treatment level. All percentages were arcsine transformed before analysis. Percentage combined survival of embryos and larvae, percentage normally developed larvae, and the percentage of larvae with vertebral anomalies were each analysed by a fixed effects, 3-way analysis of variance (ANOVA) with interaction model using SAS Proc GLM procedures (SAS 1985a). Comparisons between treatments and control(s) were performed using the Bonferroni multiple comparison procedure at $\alpha=0.05$, where appropriate (Neter et al. 1985).

Response surface methodology was used to show the relationship between normally developed larvae and the variables: temperature, salinity and terbufos con- 
Table 1. Menidia beryllina. Observed teratological responses in skeletal development of embryos and larvae, with numerical severity-index values assigned to vertebral anomalies

\begin{tabular}{cl}
\hline Value & \multicolumn{1}{c|}{ Effect } \\
\hline 0 & None observed \\
1 & Vertebral anomaly slight, in one location \\
2 & Vertebral anomalies slight, in two locations \\
3 & Vertebral anomaly severe \\
4 & Vertebral anomalies severe, and in two or \\
& more locations \\
\hline
\end{tabular}

centration. The following second order polynomial regression model was used to analyse the data

$$
\begin{gathered}
Y=b_{0} x_{0}+b_{1} x_{1}+b_{2} x_{2}+b_{3} x_{3}+b_{11} x_{1}^{2}+b_{22} x_{2}{ }^{2}+ \\
b_{33} x_{3}^{2}+b_{12} x_{1} x_{2}+b_{13} x_{1} x_{3}+b_{23} x_{2} x_{3}
\end{gathered}
$$

where $Y=$ response variable; $x_{1}, x_{2}, x_{3}=$ measured concentration of terbufos ( $\left.\mu \mathrm{g} \mathrm{l}^{-1}\right)$, salinity and temperature, respectively, and $b_{0}$ to $b_{23}$ are the estimated regression coeffcients for each term (Box \& Draper 1987).

Utilizing the coefficients provided by the multivariate regression model, 5 contour plots were constructed using the experimental levels of temperature and salinity, and data retransformed from arcsine to percentage for normally developed larvae. The 5 plots were created by fixing each of the nominal concentration levels within the model and then plotting each using the SAS Proc G3D procedure (SAS 1985b).

For each temperature level, histograms of the combined percentage survival of embryos and larvae and the percentage of normally developed larvae were produced using SAS Proc GCHART procedures (SAS 1985b).

\section{RESULTS}

Nominal and measured concentrations of terbufos at the beginning of each of the 9 tests are listed in Table 2 . Recovery was $\geq 90 \%$ with $<15 \%$ variation for all spiked samples analysed. The mean percentage dissolved oxygen (DO) saturation and $\mathrm{pH}$ for each test are summarized in Table 3 . In all tests, the DO remained above $60 \%$ saturation, with the exception of the test at $20^{\circ} \mathrm{C}$ and $5.0 \% \mathrm{~S}$ in which the measured DO in the 3 tubes at differing terbufos concentrations was below $60 \%$, but remained above $51 \%$.

Survival of seawater and acetone controls was greater than $90 \%$ for all combinations of temperature and salinity (Figs. $1 \mathrm{~A}$ to $3 \mathrm{~A}$ ), except the extreme of $20^{\circ} \mathrm{C}$ and $5.0 \%$ where survival was $55 \%$ in the seawater controls and $65 \%$ in the acetone controls (Fig. 1A). Hatching at 25 and $30^{\circ} \mathrm{C}$ was $85 \%$ or greater for embryos in seawater and acetone controls across all 3 salinities.

In the test at $20^{\circ} \mathrm{C}$ and $5 \% \mathrm{~S}, 3$ seawater control embryos and 4 acetone control embryos showed reduced cephalization, malformation of the heart with lack of circulation, and stunting of the skeletal axis. None of these embryos lived to hatching. Two additional acetone control embryos in this test developed vertebral malformations. In this case, 1 hatched embryo showed a single, slight vertebral anomaly, while 3 separate vertebral anomalies were observed in the second hatched embryo.

Hatching of controls at $20^{\circ} \mathrm{C}$ with 12.5 and $20 \% \mathrm{~S}$ remained at $80 \%$ or above (Fig. 1A), but decreased at $5 \%$ to 50 and $55 \%$ for seawater and acetone controls, respectively.

Results of the 3-way ANOVA showed a significant difference $(p=0.001)$ between the 3 temperatures for percentage embryo-larval survival across all combinations of salinity and terbufos concentrations, with survival at $20^{\circ} \mathrm{C}$ significantly reduced $(\alpha=0.05)$ from tests conducted at 25 and $30^{\circ} \mathrm{C}$. The analysis also showed a significant interaction ( $\mathrm{p}=0.004)$ between salinity and terbufos concentration. Only embryos exposed to the combination of $20 \% \mathrm{~S}$ and $100 \mu \mathrm{g}$ terbufos $\mathrm{I}^{-1}$ showed significantly lower $(\alpha=0.05)$ survival from controls, and also from embryos treated at 5 and $12.5 \% \mathrm{~S}$, and $100 \mu \mathrm{g}$ terbufos $\mathrm{l}^{-1}$.

Analysis of percentage hatch indicated a significant interaction between terbufos concentration and temperature $(p=0.0045)$, and terbufos concentration and salinity ( $p=0.0006)$, but not between temperature and salinity ( $p=0.0892)$. Figs. $1 \mathrm{~A}, 2 \mathrm{~A}$ and $3 \mathrm{~A}$ show the trend toward diminished hatching of embryos with decreas-

Table 2. Menidia beryllina. Nominal and measured exposure concentrations (in $\mu \mathrm{g} \mathrm{l} \mathrm{l}^{-1}$ ) of terbufos for tests conducted at 20,25 and

\begin{tabular}{|c|c|c|c|c|c|c|c|c|c|}
\hline \multirow{3}{*}{$\begin{array}{c}\text { Nominal } \\
\text { concentration }\end{array}$} & \multicolumn{9}{|c|}{ Measured concentration } \\
\hline & \multicolumn{3}{|c|}{$20^{\circ} \mathrm{C}$} & \multicolumn{3}{|c|}{$25^{\circ} \mathrm{C}$} & \multicolumn{3}{|c|}{$30^{\circ} \mathrm{C}$} \\
\hline & $5 \%$ & $12.5 \%$ & $20 \%$ & $5 \%$ & $12.5 \%$ & $20 \%$ & $5 \%$ & $12.5 \%$ & $20 \%$ \\
\hline 12.5 & 11.8 & 9.7 & 10.6 & 10.5 & 9.2 & 11.1 & 10.3 & 10.0 & 10.0 \\
\hline 25.0 & 20.6 & 19.7 & 20.9 & 21.1 & 20.4 & 20.8 & 20.8 & 23.2 & 20.0 \\
\hline 50.0 & 42.9 & 39.5 & 42.9 & 41.9 & 40.7 & 42.7 & 43.1 & 44.2 & 30.8 \\
\hline 100.0 & 89.1 & 84.4 & 96.1 & 90.7 & 80.3 & 87.7 & 84.4 & 91.8 & 85.2 \\
\hline
\end{tabular}
$30{ }^{\circ} \mathrm{C}$ and $5,12.5$ and $20 \% \mathrm{~S}$ 
Table 3. Menidia beryllina. Mean pH and mean percentage dissolved oxygen (DO) saturation. for tests conducted at 20,25 and $30^{\circ} \mathrm{C}$ and $5,12.5$, and $20 \% \mathrm{~S}$

\begin{tabular}{|c|c|c|c|c|c|c|c|c|c|c|c|c|}
\hline \multirow{2}{*}{$\begin{array}{l}\text { Nominal } \\
\text { concentration } \\
\left(\mu \mathrm{gl}^{-1}\right)\end{array}$} & \multicolumn{4}{|c|}{$5 \%$} & \multicolumn{4}{|c|}{$12.5 \%$} & \multicolumn{4}{|c|}{$20 \%$} \\
\hline & $\mathrm{pH}$ & Range & DO & Range & $\mathrm{pH}$ & Range & $\mathrm{DO}$ & Range & $\mathrm{pH}$ & Range & DO & Range \\
\hline \multicolumn{13}{|l|}{ At $20^{\circ} \mathrm{C}$} \\
\hline Seawater control & 6.9 & 0.31 & 80 & 10 & 7.4 & 0.53 & 93 & 7 & 7.5 & 0.15 & 98 & 3 \\
\hline Acetone control & 6.6 & 0.39 & 64 & 11 & 7.0 & 0.44 & 87 & 4 & 6.9 & 0.07 & 83 & 10 \\
\hline 12.5 & 6.7 & 0.10 & 70 & 9 & 6.9 & 0.21 & 90 & 12 & 6.9 & 0.10 & 87 & 30 \\
\hline 25.0 & 6.4 & 0.30 & 63 & 18 & 7.1 & 0.11 & 85 & 10 & 7.0 & 0.02 & 88 & 4 \\
\hline 50.0 & 6.6 & 0.22 & 69 & 6 & 7.1 & 0.08 & 82 & 19 & 7.0 & 0.02 & 83 & 3 \\
\hline 100.0 & 6.4 & 0.23 & 64 & 11 & 7.0 & 0.14 & 88 & 4 & 6.9 & 0.06 & 89 & 7 \\
\hline \multicolumn{13}{|l|}{ At $25^{\circ} \mathrm{C}$} \\
\hline Seawater control & 6.9 & 0.24 & 91 & 8 & 7.7 & 0.16 & 97 & 8 & 8.2 & 0.47 & 89 & 22 \\
\hline Aceione cuntrol & $6 . \hat{0}$ & 0. î̉ & $\bar{y} \hat{1}$ & $\hat{9}$ & 6.8 & $0.3 t$ & ys & 10 & 7.2 & 0.32 & 83 & 21 \\
\hline 12.5 & 6.8 & 0.22 & 94 & 7 & 6.9 & 0.15 & 96 & 10 & 7.4 & 0.54 & 91 & 7 \\
\hline 25.0 & 6.5 & 0.23 & 92 & 7 & 7.0 & 0.05 & 95 & 7 & 7.6 & 0.76 & 91 & 5 \\
\hline 50.0 & 6.4 & 0.36 & 89 & 9 & 6.7 & 0.06 & 97 & 8 & 7.5 & 0.29 & 86 & 13 \\
\hline 100.0 & 6.6 & 0.27 & 93 & 6 & 6.7 & 0.06 & 96 & 7 & 7.4 & 0.48 & 92 & 5 \\
\hline \multicolumn{13}{|l|}{ At $30^{\circ} \mathrm{C}$} \\
\hline Seawater control & 6.8 & 0.04 & 89 & 8 & 7.4 & 0.27 & 99 & 3 & 8.0 & 0.20 & 80 & 10 \\
\hline Acetone control & 6.4 & 0.39 & 83 & 7 & 6.7 & 0.29 & 95 & 9 & 6.9 & 0.65 & 81 & 10 \\
\hline 12.5 & 6.4 & 0.34 & 86 & 3 & 6.8 & 0.16 & 96 & 5 & 7.0 & 0.19 & 85 & 5 \\
\hline 25.0 & 6.5 & 0.21 & 90 & 4 & 6.8 & 0.16 & 96 & 7 & 7.0 & 0.13 & 84 & 10 \\
\hline 50.0 & 6.3 & 0.31 & 88 & 9 & 6.8 & 0.23 & 97 & $?$ & 7.1 & 0.24 & 78 & 4 \\
\hline 100.0 & 6.5 & 0.06 & 93 & 6 & 7.0 & 0.13 & 97 & 6 & 7.1 & 0.24 & 80 & 3 \\
\hline
\end{tabular}

ing temperature coupled with increasing salinity and increasing terbufos concentration. Hatching was significantly different between the 3 exposure temperatures, and followed a graded response - with the lowest percentage hatch occurring in tests conducted at $20^{\circ} \mathrm{C}$ and the highest percentage hatch in tests at $30^{\circ} \mathrm{C}$. The percentage of hatching embryos was also statistically lower $(\alpha=0.05)$ for all tests conducted at $20 \% \mathrm{~S}$.

Embryos exposed to terbufos expressed a broad range of developmental malformations. Reduced cephalization occurred in $5.6 \%$ of exposed embryos; primarily in the test conducted at $20^{\circ} \mathrm{C}$ and $5 \%$. Microphthalmia was observed in several embryos, but in general its occurrence was sporadic. Cardiovascular anomalies such as defects in the number and structure of heart chambers, and reduced or total lack of circulation, were exhibited in $3.4 \%$ of exposed embryos. Again, the highest frequency of occurrence was in the test conducted at $20^{\circ} \mathrm{C}$ and $5 \% \mathrm{~S}$.

Skeletal anomalies, in the form of curvature and malformations of the vertebrae, were the most severe and predominant terata observed across all combinations of temperature and salinity. Scoliosis and/or lordosis occurred in $21 \%$ of embryos exposed to terbufos, with $27 \%$ exhibiting malformations in the structure of vertebrae at one or more places along the vertebral column. An example of normally developed vertebrae from a control larvae, and examples of malformed ver-
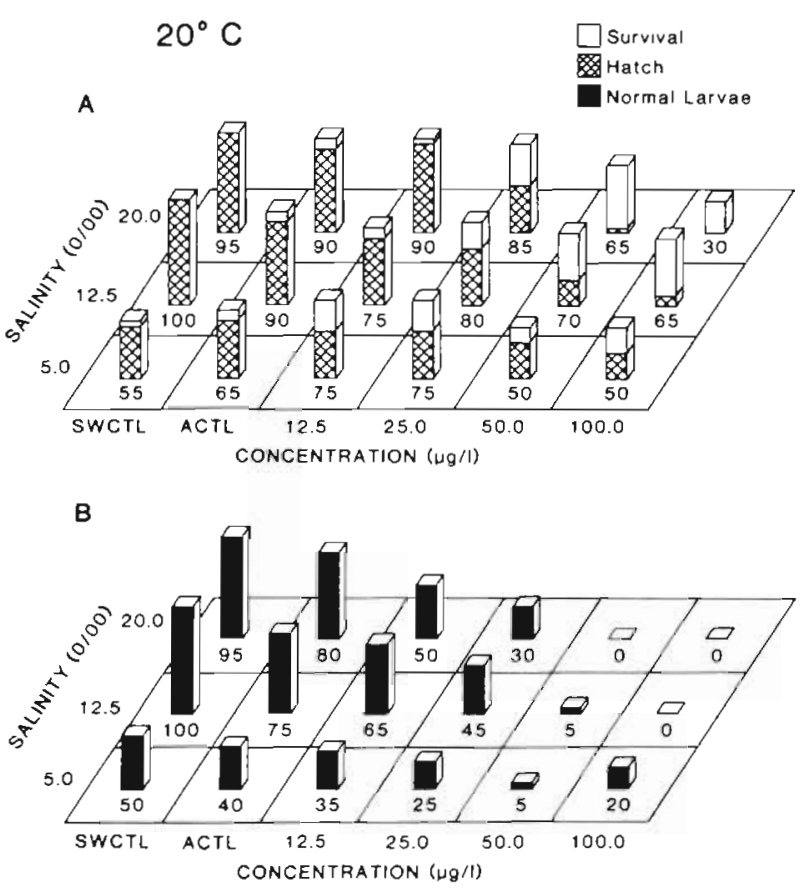

Fig. 1. Menidia beryllina. Results of blastula stage embryos exposed to terbufos at $20^{\circ} \mathrm{C}$. (A) Combined percentage survival of embryos and larvae; (B) percentage of normally developed larvae. Symbols are SWCTL saltwater control; ACTL: acetone control; the number with.n each block indicates percentage survival and percentage normally developed larvae in $A$ and $B$, respectively 


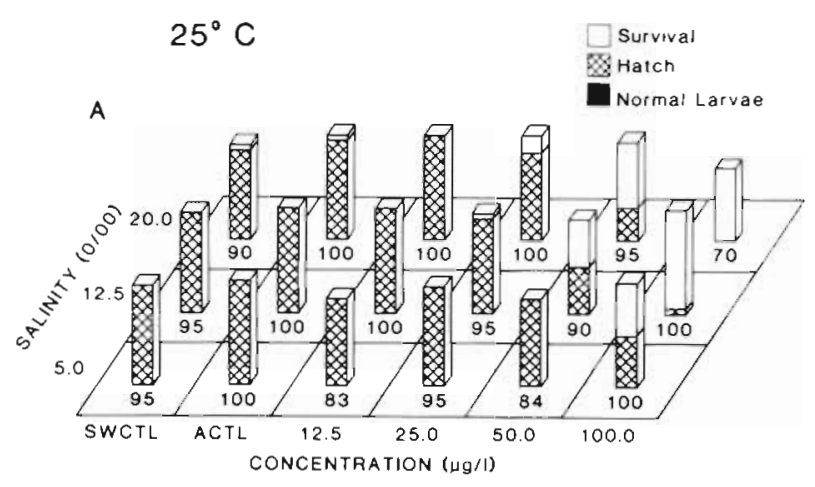

B

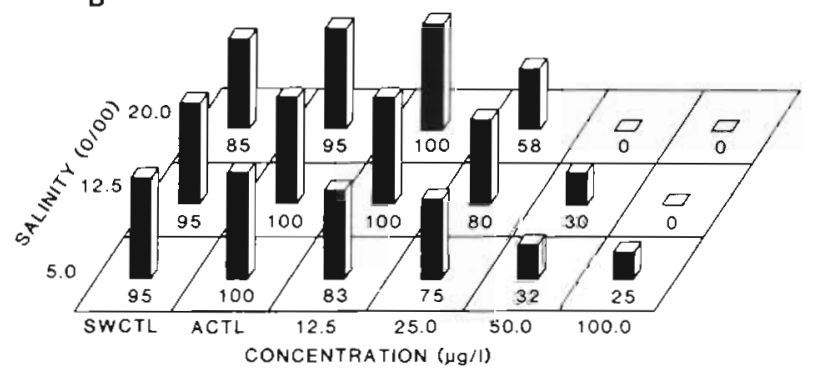

Fig. 2. Menidia beryllina. Results of blastula stage embryos exposed to terbufos at $25^{\circ} \mathrm{C}$. See Fig. 1 for further details

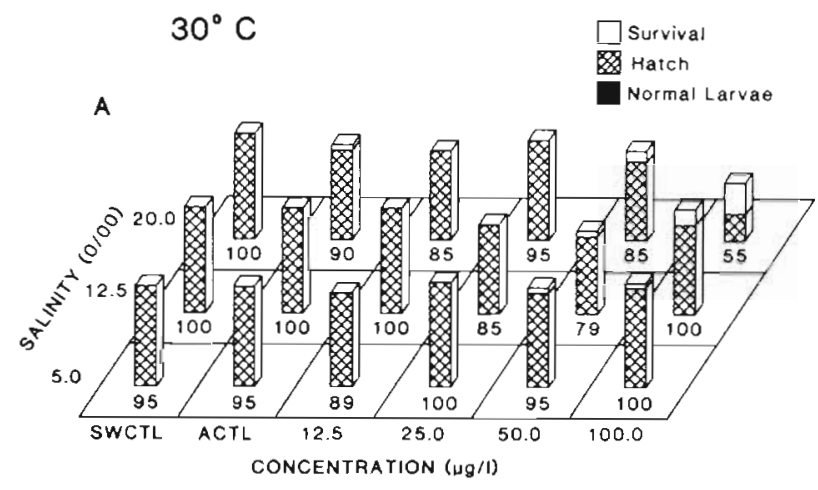

B

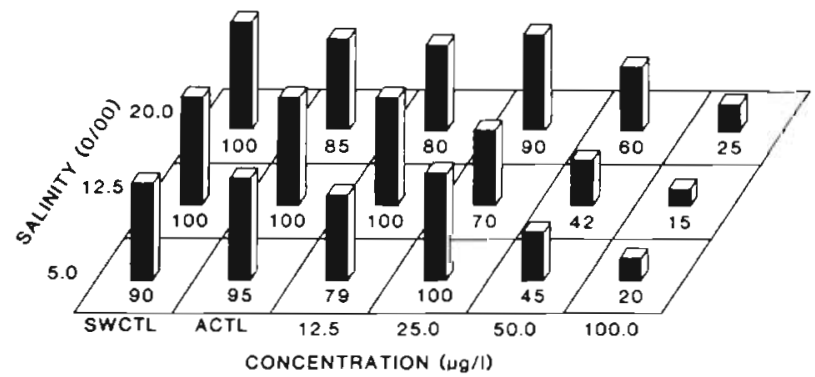

Fig. 3. Menidia beryllina. Results of blastula stage embryos exposed to terbufos at $30^{\circ} \mathrm{C}$. See Fig. 1 for further details

Table 4. Results of the multivariate regression analysis for the percentage of normal Menidia beryllina larvae from embryos exposed to terbufos; $\mathrm{C}=$ Concentration of terbufos ( $\left.\mathrm{ug} \mathrm{I^{-1 }}\right), \mathrm{S}=$ Salinity $(\%), \tau=$ Temperature $\left({ }^{\circ} \mathrm{C}\right)$

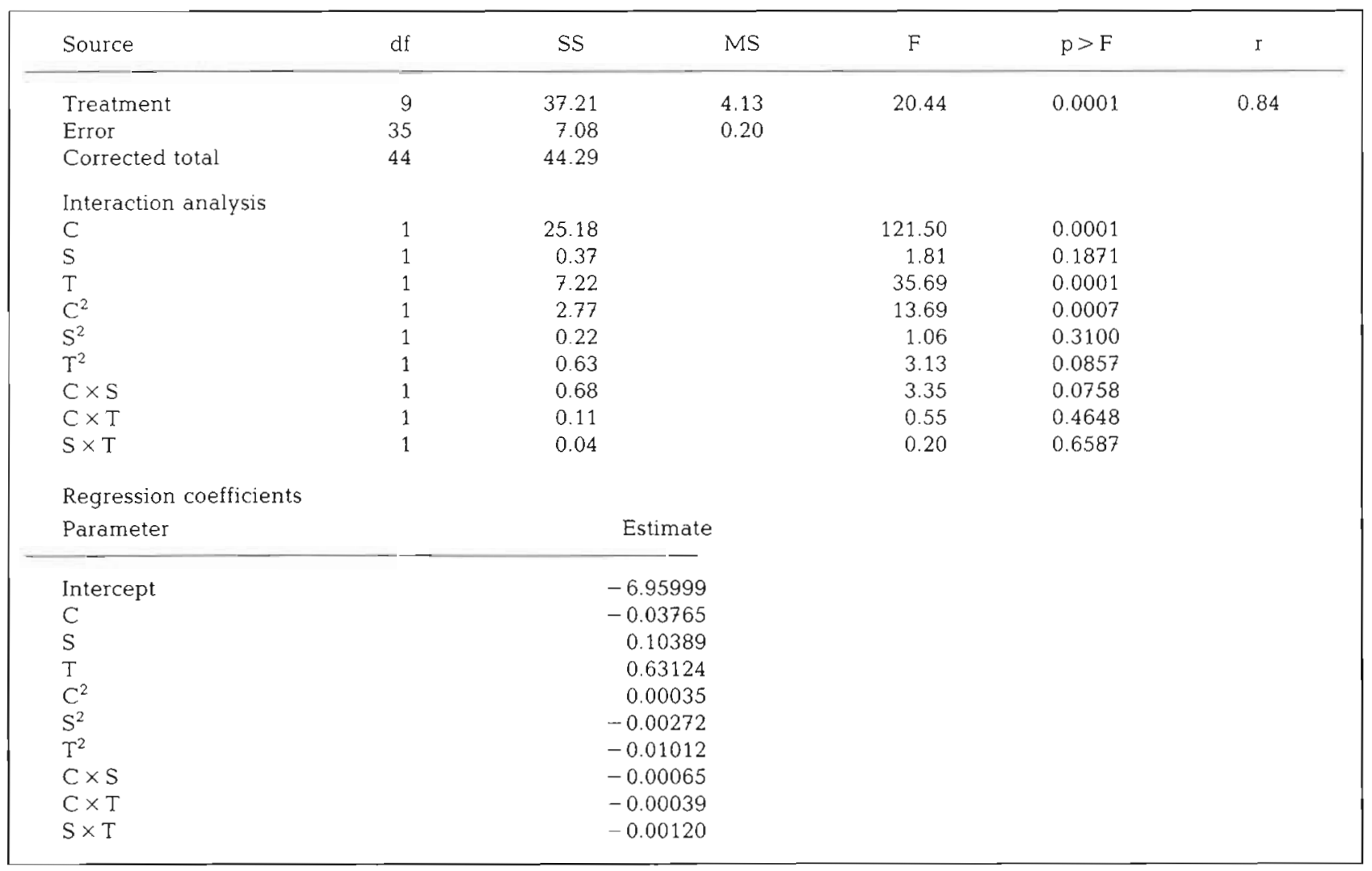



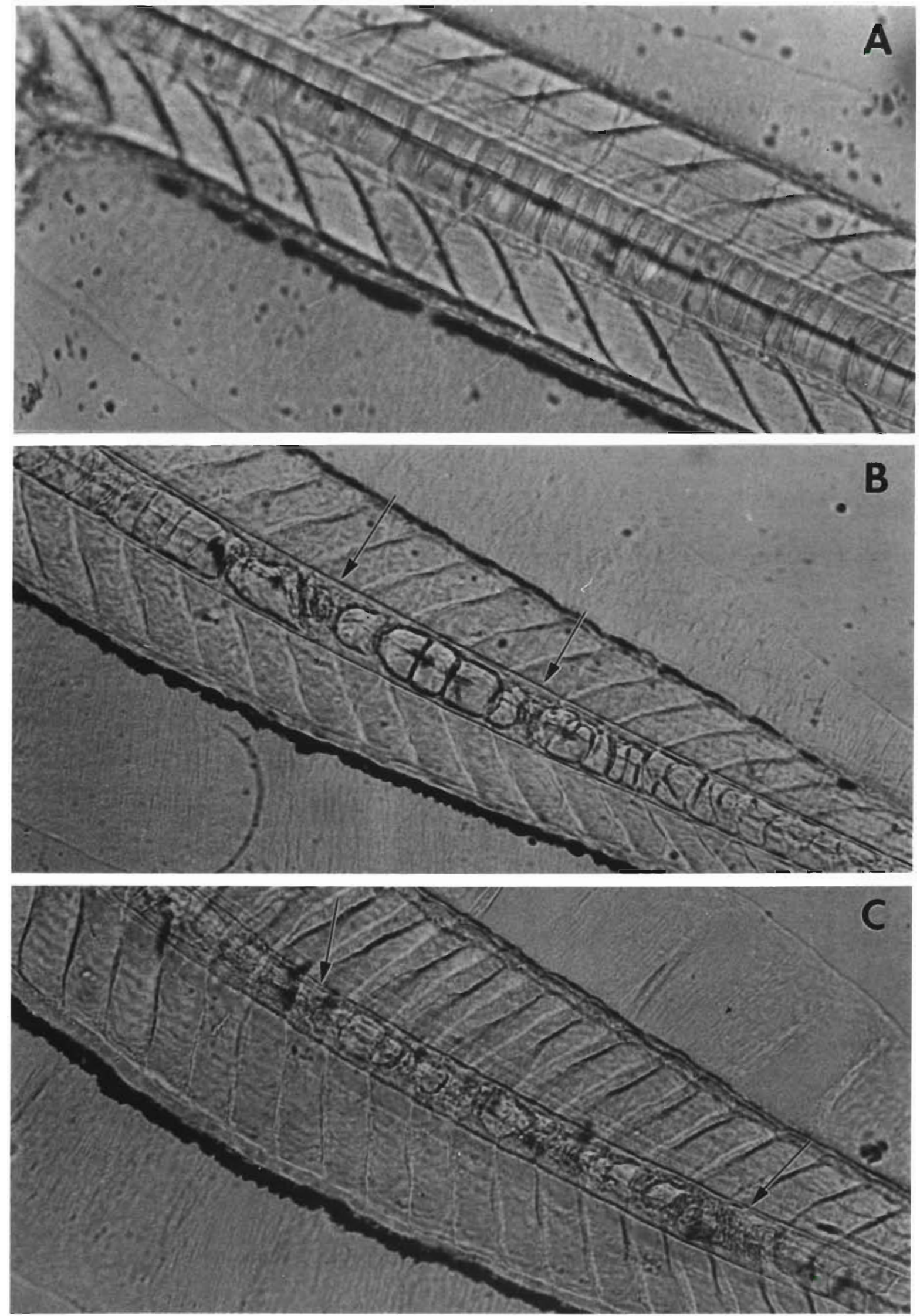

Fig. 4. Menidia beryllina. Vertebral columns of newly hatched embryos showing normal development and induced vertebral anomalies. (A) Embryo reared in clean seawater at $25^{\circ} \mathrm{C}$ and $20 \% \mathrm{~S}$ (B) embryos exposed to $25 \mu \mathrm{g}$ terbufos $\mathrm{l}^{-1}$ at $25^{\circ} \mathrm{C}$ and $12.5 \%$ $\mathrm{S}$. Arrows indicate severly malformed centra; $(\mathrm{C})$ embryo exposed to $50 \mathrm{\mu g}$ terbutos $\mathrm{l}^{-1}$ at $25^{\circ} \mathrm{C}$ and $5 \%$. Arrows indicate area of severely malformed vertebrae 
tebrae from 2 terbufos exposed hatched larvae are shown in Fig. 4. A strong relationship existed between increased incidences of vertebral damage and increasing terbufos concentration. However, no trend in the severity of the vertebral malformations was observed in relation to increasing concentrations of terbufos.

Analysis of the percentage of normal larvae without vertebral anomalies (Figs. $1 \mathrm{~B}, 2 \mathrm{~B}$ and $3 \mathrm{~B}$ ), indicated significant differences between controls and terbufos exposed embryos $(p=0.0001)$, and also among the 3 temperatures utilized $(p=0.0001)$ - with the lower temperatures associated with increasing anomalies. Salinity did not exert a significant effect ( $p=0.175)$, nor were there any significant interactions between the main factors of terbufos concentration, temperature orsalinity ( $p \geq 0.921)$. Post-hoc analysis revealed a significantly higher percentage of larvae without skeletal anomalies in controls vs embryos exposed to nominal concentrations of $25.0,50.0$ and $100.0 \mu \mathrm{g} \mathrm{l}^{-1}$ terbufos. Some larvae with vertebral anomalies were observed in the $12.5 \mathrm{\mu g} \mathrm{l}^{-1}$ treatment. Further analysis showed tests conducted at $20^{\circ} \mathrm{C}$ resulted in a significant reduction in the percentage of normal larvae, and increased skeletal anomalies of 14 and $9 \%$ when compared to tests run at 25 and $30^{\circ} \mathrm{C}$, respectively.

Results of the multivariate regression model for the percentage of normal larvae are shown in Table 4. The linear effects of concentration and temperature, and the quadratic effect of concentration are the only significant effects in the model. The response surface for the predicted percentage of normally developed larvae at each nominal concentration, for the 9 combinations of temperature and salinity is shown in Fig. 5. Temperature had the greatest predicted effect on the percentage of normal larvae. With increasing temperature an increase in the number of normal individuals was predicted. Terbufos had the opposite, predictable effect, an increase in concentration resulted in a decrease in the percentage of normally developed larvae. The predicted effect of salinity on the percentage of normal larvae was negligible, however, the plots indicate a trend toward decreasing percentages of normal larvae as salinity increases, at the higher terbufos concentrations

\section{DISCUSSION}

Developmental success in many teleosts is affected by environmental factors such as temperature, salinity, $\mathrm{pH}$ and DO, acting singly or in concert on physiological processes. Temperature and salinity tolerance ranges

Fig. 5. Menidia beryllina. Response surface for predicted percentage of normally developed larvae at each nominal terbufos concentration for the 9 combinations of temperature and salinity
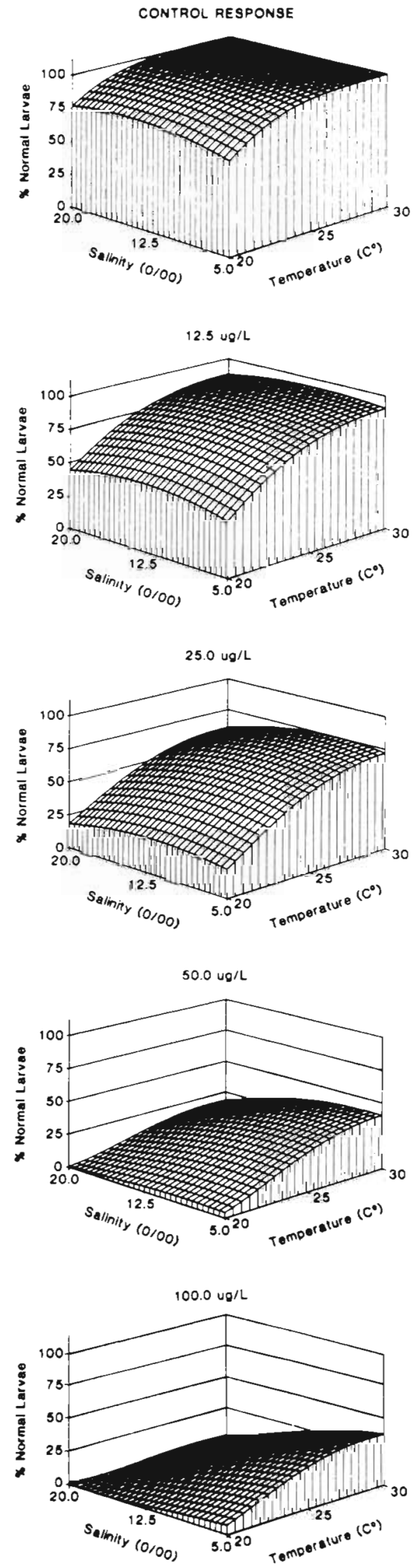
are typically narrow for marine organisms, but show a much wider range for species found in estuarine habitats. In reviews, Kinne $(1963,1964)$ described the interactive effect that temperature and salinity may have on one another. Temperature can alter the effects of salinity by increasing, decreasing, or shifting the range of salinity tolerance for a specific organism Reciprocally, salinity can alter the temperature tolerance range.

Our results show that salinity had the least effect on normal development, survival and hatching of Menidia beryllina embryos. This is not surprising in light of the euryhaline nature of the species. $M$. beryllina resides along the Atlantic and Gulf coasts as well as in freshwater rivers, lakes and reservoirs of the USA. It is found in freshwater and at salinities of $75 \%$, but estuarine populations seem to prefer salinities of $19 \%$ or less (Middaugh et al. 1987). Using an estuarine population of $M$. beryllina, Middaugh et al. (1986) demonstrated no significant differences in hatching and larval survival for embryos maintained at 5, 15 and $30 \%$ and $25^{\circ} \mathrm{C}$.

Although an interaction between salinity and terbufos concentration did influence embryo survival at their respective highest values, the most prominent influence salinity displayed was on hatching success, resulting in a slight reduction in hatching for tests conducted at $20 \%$. Figs, $1 \mathrm{~A}, 2 \mathrm{~A}$ and $3 \mathrm{~A}$ indicate a trend toward diminished hatching success with decreasing temperature, coupled with the combination of increasing salinity and terbufos concentration. Hubbs et al. (1971) reported similar temperature-salinity effects using embryos from a freshwater population of Menidia beryllina (audens) from Lake Texoma, Oklahoma. In that study, percentage embryo-larval survival at $20{ }^{\circ} \mathrm{C}$ ranged between 55 and $75 \%$, with combinations of low temperature and high salinity considerably diminishing hatching success. However, the Lake Texoma population also exhibited high survival at combinations of low temperature and low salinity. Conversely, control embryos in our study showed the lowest percentages of survival, hatching and normal development at the extreme of $20^{\circ} \mathrm{C}$ and $5 \%$. This difference in response may be attributable to restriction of the lake population to a freshwater habitat with a resultant loss of euryplasticity, and, to latitudinal differences in temperature tolerance between the 2 groups, resulting in a greater resistance to lower temperatures in the lake population.

Although the estuarine populations are euryhaline, it appears that low temperature may decrease the salinity range for optimal survival and hatching in Menidia beryllina. Our data also indicate that, regardless of temperature, embryos maintained at higher salinities are more susceptible to the effects of terbufos, resulting in a lower percentage of normal larvae. Linden et al. (1979) exposed Fundulus heteroclitus to the water soluble fraction of No. 2 fuel oil and hypothesized that an embryo at non-optimal salinities may be unable to maintain its osmoregulatory capacity due to decreasing availability of metabolic energy at lower temperatures. This, coupled with the additional stress of a toxicant on metabolic maintenance, decreases the developmental success of an embryo. Indeed, terbufos-exposed embryos at $20^{\circ} \mathrm{C}$ displayed decreased percentages of survival and hatching with increased percentages of skeletal anomalies. Weis et al. (1981) observed increased teratogenic effects of methylmercury to $F$. heteroclitus exposed at lower temperatures, and attributed the increased effects to prolongation of the developmental period thus allowing longer exposure to the toxicant during embryogenesis.

In the test conducted at $20^{\circ} \mathrm{C}$ and $5 \% \mathrm{~S}$, several seawater and acetone controls showed arrested development with subsequent degeneration of the craniofacial, carciovascular and skeletal systems resulting in death of the embryos before hatching. Research with other teleosts show that sub-optimal temperatures and salinities can influence biochemical and physiological processes leading to morphological malformations, alterations of developmental rate and lethality (Blaxter 1969, Rosenthal \& Alderdice 1976, Laale \& Lerner 1981)

Two additional acetone-control larvae in this test exhibited vertebral anomalies which were observed only in terbufos exposed individuals of the other tests conducted. Vertebral anomalies have been shown to occur frequently in both natural populations and laboratory reared fish (Gabriel 1944, Gill \& Fisk 1966, Hickey et al. 1977). A study of temperature effects on vertebral development of chinook salmon Oncorhynchus tshawytscha embryos indicated an increase in the number of vertebral anomalies at temperatures both above and below optimum (Seymour 1959). Weis \& Weis (1974) in a study of Fundulus heteroclitus embryos exposed to parathion and carbaryl, and Weis \& Weis (1976) in a later study with Menidia menidia embryos exposed to DDT (dichlorodiphenyltrichloroethane), malathion and carbaryl, found that exposures to assorted insecticides of fundamentally different chemical structure, elicited similar developmental malformations. They speculated that a species may exhibit a tendency to develop specific anomalies in response to exposure to various chemical agents. Therefore, $M$. beryllina embryos may have a tendency to develop vertebral anomalies under sub-optimal environmental conditions which are augmented by exposure to terbufos. Moreover, the observed increase in vertebral anomalies associated with increasing terbufos concentration might be a condition of enhanced susceptibility 
of biochemical, developmental and/or physiological processes to the synergistic action between suboptimal environmental factors and terbufos exposure.

Organophosphorus compounds have been shown to produce skeletal deformities such as scoliosis and lordosis in a variety of fish species. Fathead minnows Pimephales promelas and brook trout Salvelinus fontinalis chronically exposed to diazinon developed varying degrees of scoliosis and lordosis ranging from small kinks to extreme spinal displacement (Allison \& Hermanutz 1977). Diazinon was also reported to cause scoliosis and hemorrhaging around the dorsal fin in exposed Motsugo fish Pseudorasbora parva (Kanazawa 1975). Vertebral displacement with localized hemorrhaging resulting from exposure to organophosphorus compounds have also been documented by Eaton (1970) and McCann \& Jasper (1972) for bluegill Lepomis macrochirus, Kumar \& Ansari (1984) for zebrafish Brachydanio rerio and by Mount \& Boyle (1969) for brown bullheads Ictalurus nebulosus. In most cases, the above mentioned displacements and hemorrhaging may be explained by the anticholinesterase action of the compounds inducing severe neuromuscular contractions which fracture the vertebrae. The vertebral anomalies expressed by the terbufos exposed embryos in our study ranged from slight distortions of the centra to multiple fusions of vertebrae along one or more sections of the vertebral column (Fig. 4). Although the mechanism is unknown, we feel these abnormalities are not mechanically produced by flexures, but caused by toxicant induced interference of developmental processes. One explanation for the occurrence of these anomalies may be in the improper formation of collagen by the fibroblast. Mayer et al. (1978) reported a significant decrease in the collagen content of channel catfish backbones after exposure to toxaphene. They suggested that competition for Vitamin $\mathrm{C}$ by enzymatic detoxification processes with organochlorine insecticides may have resulted in a net deficiency of Vitamin $C$ necessary for collagen synthesis through the hydroxylation of proline. However Kozlovskaya \& Mayer (1984) stated that exposure of crucian carp Carassius carassius to trichlorfon (organophosphate insecticide), unlike toxaphene, did not involve hydroxyproline. Rather, diminution of collagen formation with trichlorfon was probably a function of esterase inhibition.

In conclusion, our results showed that terbufos exposure reduced embryo survival and hatching and is teratogenic to developing Menidia beryllina. These effects may be exacerbated by sub-optimal environmental conditions resulting in a lower proportion of normally developed individuals. Further studies are underway to assess the effect of embryonic terbufos exposure on vertebral development during ossification and subsequent growth.
Acknowledgements. We thank Drs J. S. Weis and P. Weis for reviewing an early version of the manuscript; and $Y$ Ford for preparing the figures.

\section{LITERATURE CITED}

Allison, D. T., Hermanutz, R. O. (1977). Toxicity of diazinon to brook trout and fathead minnows. U. S. Environmental Protection Agency, EPA Rep No. EPA-600/3-77-060. Office of Research and Development, Duluth, Minnesota

Blaxter, J. H. S. (1969). Development: eggs and lavae. In Hoar, W. S., Randall, D. J. (eds.) Fish physiology, Vol. III Reproduction and growth, bioluminesce, pigments and poisons. Academic Press, New York

Box, G. E. P., Draper, N. R. (1987). Empirical model-building and response surfaces. John Wiley \& Sons, Inc., New York

Eaton, J. G. (1970). Chronic malathion toxicity to the bluegill (Lepomis macrochirus Rafinesque). Wat. Res. 4: 673-684

Gabriel, M. L. (1944). Factors affecting the number and form of vertebrae in Fundulus heteroclitus. J. exp. Zool. 95 $105-147$

Gill, C. D., Fisk, D. M. (1966). Vertebral abnormalities in sockeye, pink and chum salmon. Trans. Am. Fish Soc. 95 $177-182$

Hickey, C. R., Young, B. H., Bishop, R. D. (1977). Skeletal abnormalities in striped bass. N. Y Fish Game J. 24: 70-85

Hubbs, C., Sharp, H. B., Schneider, J. F. (1971). Developmental rates of Menidia audens with notes on salt tolerance Trans. Am. Fish Soc. 100: 603-610

Kanazawa, J. (1975). Uptake and excretion of organophosphorus and carbamate insecticides by freshwater fish, Motsugo, Pseudorasbora parva. Bull envir. Contam. Toxic $14: 346-352$

Kinne, $0 .(1963)$. The effects of temperature and salinity on marine and brackish water animals. I. Temperature. Oceanogr mar. Biol. An. Rev. 1: 301-340

Kinne, O. (1964). The effects of temperature and salinity on marine and brackish water animals. II. Salinity and temperature, salinity combinations. Oceanogr mar Biol. An. Rev. 2: 281-339

Kozlovskaya, V. I., Mayer, F. L. (1984) Brain acetylcholinesterase and backbone collagen in fish intoxicated with organophosphate pesticides. J. Great Lakes Res. 10: 261-266

Kumar, K., Ansari, B. A. (1984). Malathion toxicity: skeletal deformities in zebrafish (Brachydanio rerio, Cyprinidae). Pestic. Sci. 15: 107-111

Laale, H. W. Lemer, W. (1981). Teratology and early fish development. Am. Zool. 21: 517-533

Lagler, K. F., Bardach, J. E., Miller, R. R., Passino, D. R. (1977) Ichthyology, 2nd edn. John Wiley and Sons Inc., New York

Linden, O., Sharp, J. R., Laughlin, J. Jr, Neff, J. M. (1979). Interactive effects of salinity, temperature and chronic exposure to oil on the survival and developmental rate of embryos of the estuarine killifish. Fundulus heteroclitus. Mar Biol. 51. 101-109

Mayer, F. L., Ellersieck, M. R. (1986). Manual of acute toxicity: Interpretation and data base for 410 chemicals and 66 species of freshwater animals. Resour. Publ. 160. U. S. Department of the Interior, Fish and Wildlife Service, Washington, D. C.

Mayer, F. L., Mehrle, P. M., Crutcher, P. L. (1978). Interactions of toxaphene and Vitamin $C$ in channel catfish. Trans. Am. Fish. Soc. 107: 326-333

McCann, J. A., Jasper, R. L. (1972). Vertebral damage to 
bluegills exposed to acutely toxic levels of pesticides. Trans. Am. Fish Soc. 101: 317-322

Middaugh, D. P., Hemmer, M. J, Goodman, L. R (1987) Methods for spawning, culturing and conducting toxicitytests with early life stages of four Atherinid fishes: the inland silverside, Menidia beryllina, Atlantic silverside, Menidia menidia, tidewater silverside, Menidia peninsulae and the California grunion, Leuresthes tenuis. U. S. Environmental Protection Agency, EPA Rept. No. EPA600/8-87/004. Office of Research and Development, Washington, D.C.

Middaugh, D. P., Hemmer, M. J., Lores, E. M. (1988). Teratological effects of 2,4-dinitrophenol, produced water' and naphthalene on embryos of the inland silverside Menidia beryllina. Dis. aquat. Org. 4: 53-65

Middaugh, D. P., Hemmer, M. J., Rose, Y L. (1986). Laboratory spawning cues in Menidia beryllina and Menidia peninsulae (Pisces: Atherinidae) with notes on survival and growth of larvae at different salinities. Envir. Biol. Fish $18(2): 107-117$

Mount, D. I., Boyle, H. W (1969). Parathion - use of blood concentration to diagnose mortality in fish. Envir. Sci. Technol. 3: 1183-1185

Neter, J., Wasserman, W., Kutner, J. (1985). Applied linear statistical models, 2nd edn. Richard D. Irwin, Inc., Homewood, Illinois

Rosenthal, H., Alderdice, D. F. (1976). Sublethal effects of environmental stressors, natural and pollutional, on marine fish eggs and larvae. J. Fish Res. Bd. Can. 33: 2047-2065

SAS Institute Inc. (1985a). SAS user's guide: statistics, Version 5 edn. Cary, North Carolina

SAS Institute Inc. (1985b). SAS/graph users guide, Version 5 edn. Cary, North Carolina

This article was presented by Dr G. Peters, Hamburg,

F. R. Germany
Seymour, A. (1959). Effects of temperature upon the formation of vertebrae and fin rays in young chinook salmon. Trans. Am. Fish Soc. 88: 58-69

Smith, G. J. (1987). Pesticide use and toxicology in relation to wildlife: organophosphorus and carbamate compounds. Resour Publ 170. Department of the Interior, Fish and Wildlife Service, Washington, D.C

Solomon, H. M., Weis, J. S. (1979). Abnormal circulatory development in Medaka caused by the insecticides carbaryl, malathion and parathion. Teratology 19: 51-62

U.S. Environmental Protection Agency (1983). Guidance for the reregistration of manufacturing-use and certain enduse pesticide products containing terbufos as the active ingredient. EPA-540/RS-83-011. Office of Pesticides and Toxic Substances, Washington, D.C.

U.S. Environmental Protection Agency (1987). Health advisories for 50 pesticides. PB88-113543, Office of Drinking Water, Washinqton, D.C.

Weis, J. S., Weis, P. (1976). Optical malformations induced by insecticides in embryos of the silversides, Menidia menidia. Fish. Bull. U. S. 74: 208-211

Weis, J. S., Weis, P. (1977). Effects of heavy metals on development of the killifish, Fundulus heteroclitus. J. Fish Biol. 11 $49-54$

Weis, J. S., Weis P., Ricci, J. L. (1981). Effects of cadmium, zinc, salinity and temperature on the teratogenicity of methylmercury to the killifish, Fundulus heteroclitus Rapp. P.-v. Réun. Cons. perm. int. Explor. Mer. 178: 64-70

Weis, P., Weis, J. S. (1974). Cardiac malformations and other effects due to insecticides in embryos of the killifish, Fundulus heteroclitus. Teratology 10: 263-267

Weis, P., Weis, J. S. (1982). Toxicity of methylmercury, mercuric chloride, and lead in killifish, Fundulus heteroclitus from Southhampton, New York. Envir. Res. 28: 364-374

Manuscript first received: October 25, 1989

Revised version accepted: February 9, 1990 